Aqueous solution-based synthesis and deposition of crystalline In-Ga-Zn-oxide films with an enhanced mobility

Peer-reviewed author version

BONNEUX, Gilles; ELEN, Ken; Menghini, Mariela; MARCHAL, Wouter; D'HAEN, Jan; Locquet, Jean-Pierre; HARDY, An \& VAN BAEL, Marlies (2018) Aqueous solution-based synthesis and deposition of crystalline In-Ga-Zn-oxide films with an enhanced mobility. In: Journal of sol-gel science and technology, 87(2), p. 310-318.

DOI: $10.1007 / \mathrm{s} 10971-018-4740-9$

Handle: http://hdl.handle.net/1942/28204 


\section{Aqueous solution-based synthesis and deposition of crystalline In-Ga-Zn-oxide films with an enhanced mobility}

G. Bonneux, $1 \square$

Phone +3211268307

Email gilles.bonneux@uhasselt.be

K. Elen, 1

M. Menghini, 2

W. Marchal, 1

J. D’Haen, 3

J. P. Locquet, 2

A. Hardy, 1

M. K. Van Bael, 1

1 Institute for Materials Research (IMO), Inorganic and Physical Chemistry, and IMEC vzw, division IMOMEC, UHasselt, Hasselt University, Martelarenlaan 42, Hasselt, 3500 Belgium

2 Dept. Physics \& Astronomy, KU Leuven, Celestijnenlaan 200D, Leuven, 3001 Belgium

3 Institute for Materials Research (IMO), Electrical and Physical Characterisation, and IMEC vzw, division IMOMEC, UHasselt, Hasselt University, Martelarenlaan 42, Hasselt, 3500 Belgium

Received: 8 March 2018 / Accepted: 5 July 2018

\section{Abstract}

In-Ga-Zn-oxide (IGZO), in its amorphous state, is known to have a high electron mobility and low off-state current inside transistor devices, which may even be further improved by crystallization. Thin films of the IGZO 
superlattice structure require an optimal layer homogeneity in addition to precise control of the stoichiometry, which can be achieved by using a solution-based process. In this work, an aqueous precursor system is developed, starting from the respective metal (hydr)oxides. A stable multimetal precursor is obtained, which is ideally suited for solutiondeposition via spin-coating. Through an optimized multi-step thermal treatment, crystalline thin films of IGZO are obtained that show a preferential c-axis orientation after rapid-thermal annealing at $1000{ }^{\circ} \mathrm{C}$ in inert conditions. The resulting film shows a good optical transparency $(>0 \%)$ and an improved carrier mobility $\left(27.2 \mathrm{~cm}^{2} / \mathrm{Vs}\right)$ compared to typical solution-processed amorphous IGZO films, and is therefore promising for further application.

Top: Overview of the precursor synthesis, which consists of the metal (hydr)oxides as a starting product, citric acid (ligand) and ammonia ( $\mathrm{pH}$ adjustment and bridging ion). Middle: Schematic route of the film processing. The precursor is applied on a substrate via spincoating. Intermediate hotplate steps $\left(200-400-600^{\circ} \mathrm{C}\right)$ decompose the precursor into an oxide film. Finally, a thermal treatment $\left(1000^{\circ} \mathrm{C}\right)$ inside an RTP (double-substrate setup) crystallizes the oxide films. Bottom: Thermogravimetric plot of the thermal decomposition of the precursor solution // Plane view SEM micrograph of the film morphology after annealing at $1000{ }^{\circ} \mathrm{C}$ for $500 \mathrm{~s} / / \mathrm{XRD}$ diffractogram of the film after annealing at $1000^{\circ} \mathrm{C}$ for $500 \mathrm{~s}$.

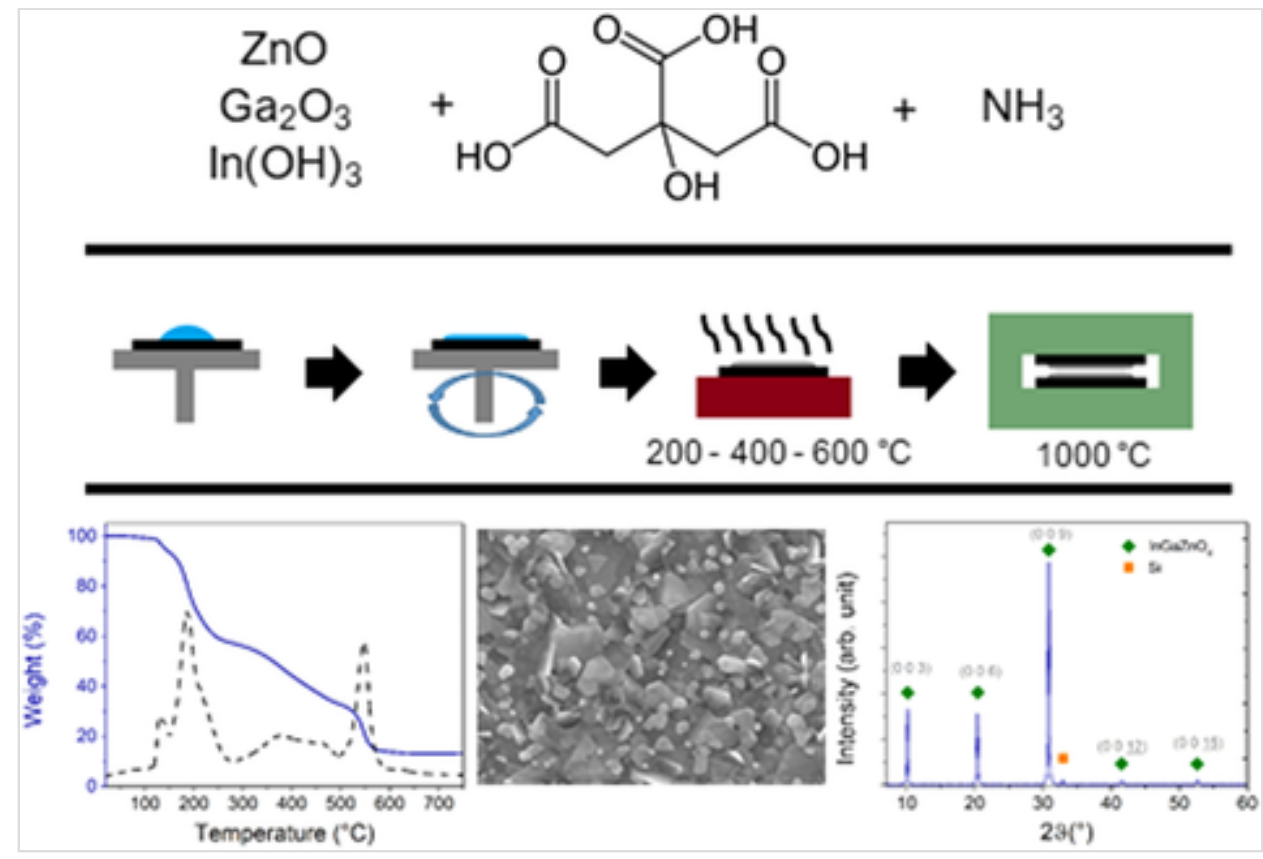


- Solution-based deposition starting from an aqueous multimetal citrate precursor system

- Crystalline IGZO films that show a preferential c-axis orientation after annealing at $1000^{\circ} \mathrm{C}$

- An improved carrier mobility compared to typical solution-processed amorphous IGZO films

- A good optical transparency has been observed in the visible-light range

\section{Keywords}

IGZO

Sol-gel

Transparent conducting oxide (TCO)

Chemical solution deposition (CSD)

Thermal decomposition

Carrier mobility

\section{Introduction}

Over the last decades, there has been an increased interest towards oxide-based semiconductor materials for various opto-electronic applications. Especially in display technologies, In-Ga-Zn based oxides (IGZO) are expected to take over the future market which was until recently mostly dominated by silicon (both amorphous and polycrystalline) or organic semiconductors [1]. Much attention has been given to amorphous IGZO (a-IGZO) due to its suitability as a TFT channel material (with carrier mobilities often reaching over $10 \mathrm{~cm}^{2} / \mathrm{Vs}$ ), low off-state current [2] and ease of processing. In order to further improve device performance, crystalline IGZO (c-IGZO, $\operatorname{InGaO}_{3}(\mathrm{ZnO})_{m}$, where $m$ is an integer) is a promising candidate which shows even higher carrier mobilities which may lead to an improved device performance [3]. The crystal structure consists of a superlattice, which is already widely reported in literature [4, 5, 6, 7]. Following this concept, epitaxial IGZO layers have been reported, which typically require using single crystalline substrates (such as YSZ, sapphire,..) in combination with a sacrificial $\mathrm{ZnO}$ template layer $[5,6,7,8]$. Despite very high processing temperatures $\left(>1400{ }^{\circ} \mathrm{C}\right)$ and limited substrate options, the fabricated layers showed a greatly improved carrier mobility $\left(>80 \mathrm{~cm}^{2} / \mathrm{Vs}\right)$ [9]. The characteristics and properties of polycrystalline (pc) IGZO have not been studied as detailed as their amorphous and epitaxial counterparts. Yet, over the last few years, 
nanocrystalline IGZO films, which are often produced with a c-axis alignment (CAAC) and no defined grain boundaries in the a-b plane, have attracted some interest by yielding excellent device characteristics [10,11]. Therefore, this work attempts to further bridge the gap by investigating the processing steps and opto-electrical properties of pc-IGZO which is deposited via a solution-based route.

Typically, solution deposition of IGZO starts from metal nitrates and/or acetates which are dissolved in 2-methoxyethanol (2-ME) [12, 13, 14, 15, 16], often adding ethanolamine as a stabilizing agent. Despite leading to facile film depositions, 2-ME has harmful and teratogenic properties [17]. One of the features of 2-ME is the rather high dielectric constant of 17 [18], which enables a relatively high solubility of common metal salts.

In this work, water is explored as an environmentally friendly and inexpensive alternative which also benefits from a high polarity and dielectric constant. To this end, an aqueous precursor system is described for thin film deposition via spin-coating, in which the metal ions are stabilized by $\alpha$-hydroxy carboxylic acids as ligands. These precursor systems also require a careful $\mathrm{pH}$-regulation in order to prevent hydrolysis of the individual metal salts, which is to be avoided. A possible issue with these precursor systems which form amphoteric metal oxides can occur when solution-processing several layers on top of each other. From previous research on $\mathrm{ZnO}$ films [19], dissolution of underlying layers was found to take place due to the reactivity of the precursor solution towards the deposited oxide, impeding the increase of the layer thickness. Here we demonstrate that this effect can be minimized by saturating the precursor solution with the starting (hydr)oxide. All of the abovementioned challenges were successfully overcome by optimizing the precursor properties, the solutiondeposition process and the post-deposition processing steps. The opto-electrical properties of the resulting films were studied in detail, providing more insight into the effect of crystallization on the behavior of electrical conductivity of the IGZO films.

\section{Experimental work}

\subsection{Precursor synthesis}

The individual aqueous metal citrate precursors were synthesized as follows:

In(III) citrato-precursor: $\operatorname{In}(\mathrm{OH})_{3}$ (Umicore Electro-Optic materials) was dissolved in a concentrated aqueous solution of citric acid (Sigma-Aldrich, 99\%; 4:1 molar ratio with the metal ion). The mixture was refluxed for 90 min at 120 
${ }^{\circ} \mathrm{C}$. After cooling down, the acidity of the solution was lowered by adding aqueous $\mathrm{NH}_{3}$-solution (VWR, 32\%, GPR Rectapur), while carefully monitoring the $\mathrm{pH}$. The final $\mathrm{pH}$ was set at a value of 7 . This resulted in a clear, colorless solution.

$\mathrm{Zn}(\mathrm{II})$ citrato-precursor: $\mathrm{ZnO}$ (Sigma-Aldrich, ACS reagent $>99.0 \%$, puriss. p.a.) and citric acid were dissolved in water in a 1:1 molar ratio. The mixture was stirred thoroughly, after which an aqueous $\mathrm{NH}_{3}$-solution was added in order to increase the $\mathrm{pH}$ towards 7 . This resulted in a clear, light yellow solution [19].

Ga(III) citrato-precursor: $\mathrm{Ga}_{2} \mathrm{O}_{3}$ (Alfa Aesar, 99.99\%, metals basis) and citric acid were mixed together in a 1:2 molar ratio, and refluxed overnight (temperature set at $120^{\circ} \mathrm{C}$ ) after adding a small amount of water. The resulting slurry was dissolved in a $\mathrm{NH}_{3}$-solution and was stirred while continuously heating for $72 \mathrm{~h}$. The resulting solution was filtered and the $\mathrm{pH}$ was adjusted towards 7 when needed.

For each of the precursors, the solution was saturated by further adding the starting (hydr)oxide beyond the dissolution limit, at which it was stirred for 14 days. Afterwards, the solutions were filtered over a $0.1 \mu \mathrm{m}$ filter (Pall Supor100) in order to remove the precipitates.

The individual citrato precursors were combined stoichiometrically in a $1: 1: 1$ metal ratio, after the metal ion concentration was determined by inductively coupled plasma-atomic emission spectroscopy (ICP-AES, Optima 3300, PerkinElmer). The total metal ion concentration in the multimetal precursor was set at $0.42 \mathrm{M}$. Finally, the precursor was stirred overnight at room temperature and filtered before use (Pall Acrodisc PSF syringe filter, $0.2 \mu \mathrm{m}$ ).

Gels were formed by drying the precursor solution at $80{ }^{\circ} \mathrm{C}$ inside a drying stove under atmospheric conditions (Binder ED53). Afterwards, the gel was milled down into a powder for further analysis, using an agate mortar.

\subsection{Film deposition and post-deposition processing}

Both $\mathrm{Si} / \mathrm{SiO}_{2}(200 \mathrm{~nm}$ thermal oxide, processed at IMEC, $25 \times 25 \mathrm{~mm})$ and fused silica substrates (Neyco, NEGS2, $25 \times 25 \mathrm{~mm}$ ) were pre-treated using an SPM/APM cleaning procedure in order to remove possible organic contaminants and to improve the wetting of the aqueous precursor. Bath 1 (SPM) consisted of a concentrated $\mathrm{H}_{2} \mathrm{SO}_{4}-\mathrm{H}_{2} \mathrm{O}_{2}$ mixture, while the second bath (APM) contained a diluted $\mathrm{NH}_{4} \mathrm{OH}-\mathrm{H}_{2} \mathrm{O}_{2}$ mixture. After the cleaning procedure, the samples were stored under aqueous conditions for a maximum period of two weeks. 
A stack of multiple IGZO layers was deposited by spin-coating (Polos Spin150i, $3000 \mathrm{rpm}, 30 \mathrm{~s}, 1000 \mathrm{rpm} / \mathrm{s}$ ) the IGZO precursor on both thermally grown $\mathrm{SiO}_{2}$ and fused silica. After each layer, the samples were dried and pre-annealed for 2 min on hotplates at 200,400 , and $600{ }^{\circ} \mathrm{C}$ under ambient conditions. This process was repeated until the desired film thickness was achieved.

Following the deposition process, the film samples were annealed for $500 \mathrm{~s}$ at $1000{ }^{\circ} \mathrm{C}$ in a rapid-thermal processor (RTP, Annealsys AS-One $100,1{ }^{\circ} \mathrm{C} / \mathrm{s}$ ramp rate). All anneals were performed in a nitrogen atmosphere (Air Liquide, alphagaz) using a flow rate of $1 \mathrm{~L} / \mathrm{min}$. A double-substrate setup was used here, in which two samples were stacked with their coated sides facing each other. A similar setup was already proposed in previous literature, when doing hightemperature processing of crystalline IGZO films $[5,6,7]$.

\subsection{Film and gel characterization}

Thermal decomposition of the powdered gel was monitored via thermogravimetric analysis (TGA, TA Instruments Q-500, ramp rate: $10^{\circ} \mathrm{C} / \mathrm{min}$ ) under a dry air flow $(90 \mathrm{ml} / \mathrm{min})$. TGA coupled with mass spectroscopy (TGMS, TA instruments TGA Q5000, Pfeiffer quadrupole MS, High-T Pt sample pan, ramp rate: $10^{\circ} \mathrm{C} / \mathrm{min}$ ) was similarly performed under a dry air flow of 35 $\mathrm{ml} / \mathrm{min}$.

The morphology and the layer thicknesses of the processed films were analyzed via scanning electron microscopy (SEM, FEI Quanta 200 FEG). Two imaging modes (SE: secondary electron imaging, BSE: backscattered electron imaging) are used to reveal the morphology (SE) or compositional contrast (BSE). Phase determination of the film samples was done via X-ray diffractometry (XRD, Bruker D8, step size: $0.04^{\circ}$, step time: $3 \mathrm{~s}$ ). Rocking curve measurements were performed under a 2 -theta angle of $31.045^{\circ}$, while the incident angle was varied between $2-30^{\circ}$ (step size: $0.04^{\circ}$, step time: $2 \mathrm{~s}$ ). For the comparative rocking curve measurements, film samples annealed at lower temperatures and with the same post-deposition process as described above were used (with the final temperature varying between $700-900{ }^{\circ} \mathrm{C}$ ).

Film transparency was measured via UV-Vis spectroscopy (Agilent Cary 5000, UV-Vis-NIR spectrophotometer, range: $200-1200 \mathrm{~nm}$, step size: $1 \mathrm{~nm}$ ).

Sheet resistance and Hall voltage were determined by 4-point measurements using the Van der Pauw electrode configuration. The different voltages were measured, while applying a constant current $(I=10 \mathrm{~mA})$, with a Keithley 4200 SCS parameter analyzer and the sample was mounted in a variable temperature 
Lakeshore CPX-VF probe station. For the Hall measurements, the magnetic field was swept between -2 and +2 Tesla (with intervals of $0.2 \mathrm{~T}$ ), perpendicular to the sample surface.

\section{Results and discussion}

\subsection{Precursor synthesis}

Metal (hydr)oxides were chosen as starting products instead of the typical nitrate salts used in 2-ME based precursors. By avoiding the addition of nitrates to the precursor solution (leading to $\mathrm{NH}_{4} \mathrm{NO}_{3}$ ), the thermal decomposition process will be less violent, which results in an overall improved film quality. Because of the poor solubility in water, citric acid $\left(\mathrm{H}_{3} \mathrm{Cit}\right)$ was added as a ligand due to its excellent coordinative properties $[20,21]$.

In literature, structural studies of metal citrate complexes are not uncommon, often due to their biological or medical application. For gallium, the trinuclear complex $\left(\left[\mathrm{Ga}_{3}\left(\mathrm{H}_{-1} \mathrm{Cit}\right)_{3}(\mathrm{OH})\left(\mathrm{H}_{2} \mathrm{O}\right)\right]^{4-}\right)$ was shown to be dominant for a citrate/metal-ratio of 1:1 under neutral $\mathrm{pH}$ conditions [22, 23]. For higher citrate to gallium ratios, as is the case in our study, the typical mononuclear complex is observed in which two fully deprotonated citrate ligands coordinate to the $\mathrm{Ga}^{3+}$ center in an octahedral fashion. The tridentate coordination for each citrate anion occurs via two carboxylate groups and the single alkoxy group [24].

For zinc, a complex structure similar to the abovementioned gallium is reported for citrate/metal-ratios of 2:1 and higher $[25,26]$. For the $1: 1$ ratio, the lone citrate will be threefold coordinated, while the remaining coordinative positions are potentially taken up by water molecules. Beyond $\mathrm{pH} 7$, the dinuclear $\left[\mathrm{Zn}_{2}\left(\mathrm{H}_{-1} \mathrm{Cit}\right)_{2}\right]^{4-}$ was observed as significant species in solution $[27,28]$.

For indium, it has been reported that for low citrate to metal ratios there are multiple equilibria at play, which typically result in polynuclear complexes [29]. For high citrate to metal ratios, each $\mathrm{In}^{3+}$ center is coordinated by 3 bidentate citrato ligands, resulting in the octahedrally coordinated $\left[\mathrm{In}(\mathrm{Cit})_{2}\left(\mathrm{H}_{-1} \mathrm{Cit}\right)\right]^{7-}$ at neutral $\mathrm{pH}$ values [29].

At neutral $\mathrm{pH}$, this resulted in stable metal citrate complexes, although an excess of ligand was typically needed in order to easily achieve full dissolution. A great advantage to this route is that the individual metal citrate precursors are easily combined, since there are no $\mathrm{pH}$ variations and no counterions present (besides $\mathrm{NH}_{4}^{+}$), which can disturb the chemical equilibria and the stability of the citrate complexes. 
During the initial drying and heating of the precursor solution, the $\mathrm{NH}_{4}{ }^{+}$ions (which were introduced during the $\mathrm{pH}$ adjustment) will also take up the role of bridging ions between the individual citrate complexes. This way, a network is formed, leading to a stable and uniform precursor gel [21].

\subsection{Thermal decomposition of the precursor gel}

The thermal decomposition of the precursor gel under dry air atmosphere takes place in four steps: region I $\left(100-160^{\circ} \mathrm{C}\right)$, region II $\left(160-270{ }^{\circ} \mathrm{C}\right)$, region III $\left(270-500{ }^{\circ} \mathrm{C}\right)$, and region IV $\left(500-600{ }^{\circ} \mathrm{C}\right)$. The full decomposition profile can be seen in Fig. 1 and an overview of the evolved mass fragments are given below in Fig. 2 and Table 1 [19, 30, 31].

\section{Fig. 1}

Thermogravimetric analysis of the decomposition of the IGZO-precursor gel dried at $80{ }^{\circ} \mathrm{C}$. Both the decomposition profile (solid line) and the first derivative curve (dashed line) are given

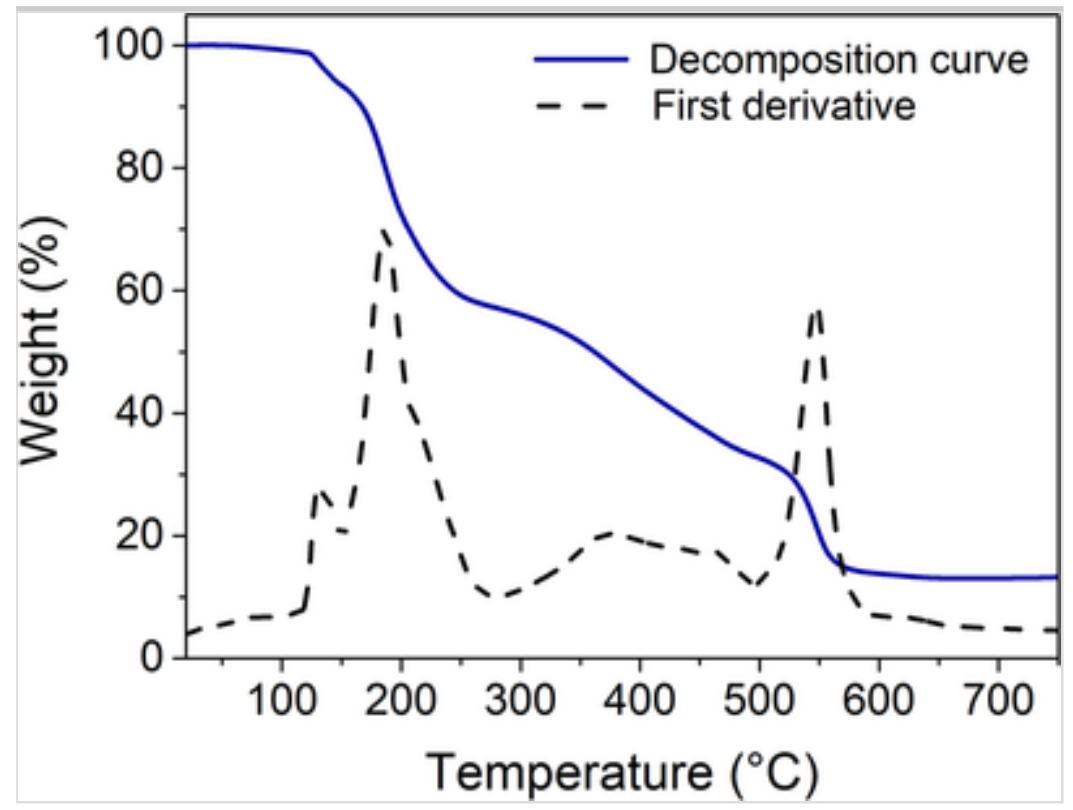

\section{Fig. 2}

TG-MS ion currents for the decomposition related $\mathrm{m} / \mathrm{z}$ values (color legend on the right), detected during the same thermal profile as illustrated in Fig. 1 (color figure online) 


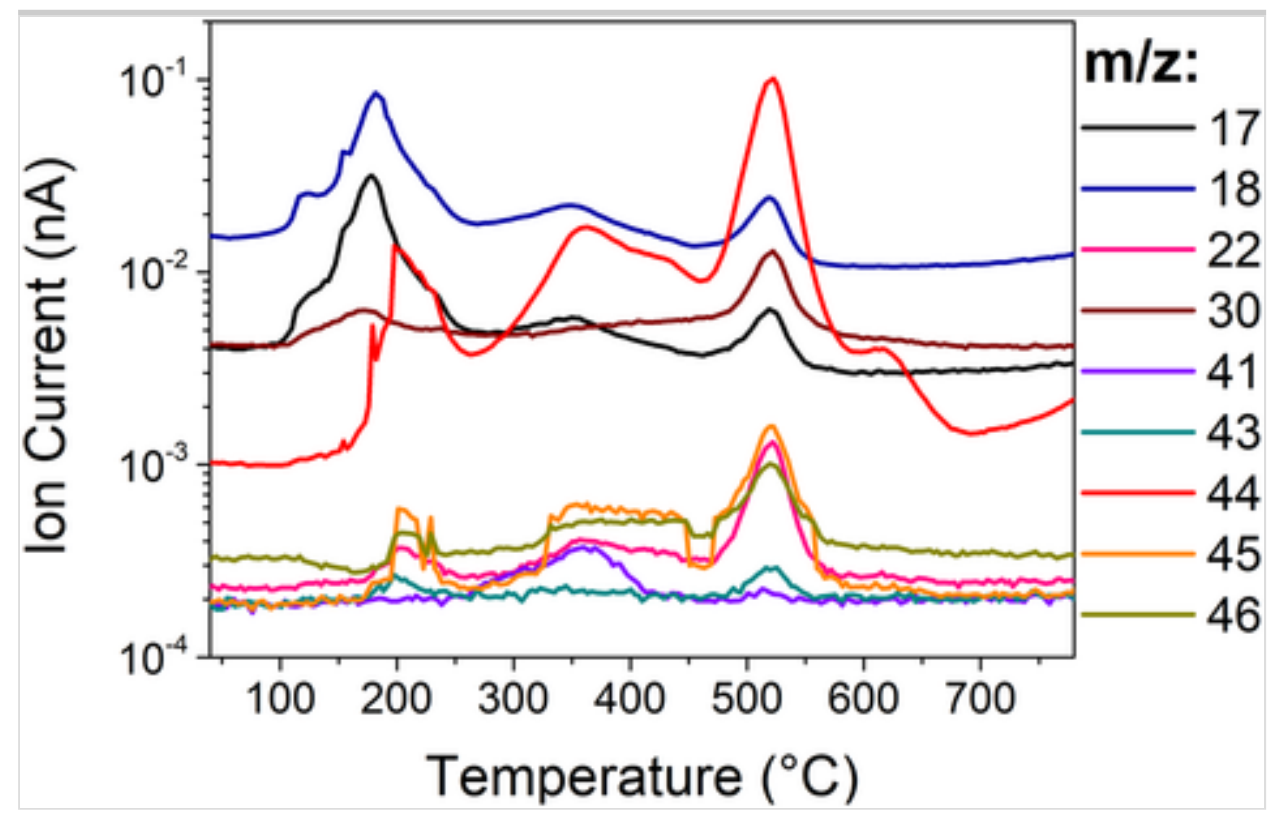

\section{Table 1}

Evolved gas analysis overview, presenting the detected mass fragment ions for each decomposition step

\begin{tabular}{|l|l|l|}
\hline & $\begin{array}{l}\text { Temperature } \\
\text { range }\left({ }^{\circ} \mathbf{C}\right)\end{array}$ & \multicolumn{1}{|c|}{ Evolved fragments $(\mathbf{T G}-\mathbf{M S}$ m/e $)$} \\
\hline $\begin{array}{l}\text { Region } \\
\text { I }\end{array}$ & $100-160$ & $\mathrm{OH}, \mathrm{NH}_{3}(17)-\mathrm{H}_{2} \mathrm{O}(18)-\mathrm{NO}(30)^{\mathrm{a}}$ \\
\hline $\begin{array}{l}\text { Region } \\
\text { II }\end{array}$ & $180-270$ & $\begin{array}{l}\mathrm{OH}, \mathrm{NH}_{3}(17)-\mathrm{H}_{2} \mathrm{O}(18)-\mathrm{CO}_{2}(22,44,45)-\mathrm{CH}_{2} \mathrm{NH}_{2}, \\
\mathrm{NO}(30)-\mathrm{HNCO}(43)-\mathrm{COOH}(45)-\mathrm{NO}_{2}(46)\end{array}$ \\
\hline $\begin{array}{l}\text { Region } \\
\text { III }\end{array}$ & $270-500$ & $\begin{array}{l}\mathrm{OH}, \mathrm{NH}_{3}(17)-\mathrm{H}_{2} \mathrm{O}(18)-\mathrm{CO}_{2}(22,44,45)-\mathrm{CH}_{2} \mathrm{NH}_{2}, \\
\mathrm{NO}(30)-\mathrm{CH}_{2} \mathrm{CCNH}(41)-\mathrm{COOH}_{4}(45)-\mathrm{NO}_{2}(46)\end{array}$ \\
\hline $\begin{array}{l}\text { Region } \\
\text { IV }\end{array}$ & $500-600$ & $\begin{array}{l}\mathrm{OH}, \mathrm{NH}_{3}(17)-\mathrm{H}_{2} \mathrm{O}(18)-\mathrm{CO}_{2}(22,44,45)-\mathrm{CH}_{2} \mathrm{NH}_{2}, \\
\mathrm{NO}(30)-\mathrm{CH}_{3} \mathrm{C}=\mathrm{O}(43)-\mathrm{COOH}_{4}(45)-\mathrm{NO}_{2}(46)\end{array}$ \\
\hline \begin{tabular}{l} 
aTentative assignment \\
\hline
\end{tabular} &
\end{tabular}

In the first decomposition region $\left(<160^{\circ} \mathrm{C}\right)$, most mass loss originates from the evaporation of residual $\mathrm{H}_{2} \mathrm{O}$, together with $\mathrm{NH}_{3}$ evolution coming from the considerable amount of ammonium citrate present in the precursor system. Ammonia evolution continues until the end of region II $\left(260-270{ }^{\circ} \mathrm{C}\right)$, which results in the formation of residual amides and/or imides which will typically decompose above $300{ }^{\circ} \mathrm{C}$ [30]. An additional source of $\mathrm{H}_{2} \mathrm{O}$ evolution can be detected in region II, where the dehydroxylation of ammonium citrate occurs. This is combined with a sharp onset of the $m / z=44$ signal around $175^{\circ} \mathrm{C}$ (and a second maximum at $200{ }^{\circ} \mathrm{C}$ ), where the strong $\mathrm{CO}_{2}$ signal can be ascribed to the citrate decarboxylation reaction. For the $\mathrm{Zn}$-citrate precursor complex, it could 
clearly be observed that the dehydroxylation and subsequent decarboxylation of the ligands [30] take place at temperatures near $340{ }^{\circ} \mathrm{C}$, corresponding to decomposition region III for our system. Since the precursor in this work is a multimetal system, there will be a temperature spread over which the three (or possibly more) individual metal complexes will start to lose their ligand coordination sphere. For our precursor, this gradual process takes place between 330 and $445^{\circ} \mathrm{C}$, with a decarboxylation maximum at $360^{\circ} \mathrm{C}$. During this process, it can be assumed that the oxide formation starts, even though there still is a significant amount of residual fraction (around $20 \%$ of the total weight) to be decomposed in the final step. This step consists of the oxidative decomposition, involving oxygen from the applied gas, forming high amounts of $\mathrm{CO}_{2}, \mathrm{NO}_{X}$, and $\mathrm{H}_{2} \mathrm{O}$ alongside some organic backbone fragments. The system is fully decomposed at a temperature of $600{ }^{\circ} \mathrm{C}$ with a residual weight of $12.9 \%$.

\subsection{Phase formation}

XRD experiments demonstrate that the film crystallinity increases drastically with annealing temperature, starting from around $700{ }^{\circ} \mathrm{C}$. Figure 3 (left) shows the individual $\theta-2 \theta \mathrm{XRD}$-diffractogram for a $1000^{\circ} \mathrm{C}$ annealed sample (reference: PDF nr. 00-038-1104, rhombohedral, R-3m). No intermediate or secondary phases could be detected, other than the presence of the Si substrate peak at $32.9^{\circ}$. The resulting film is phase-pure within the detection limits of the method and shows a strong intensity for the $\left(\begin{array}{lll}0 & 0 & \mathrm{n}\end{array}\right)$-lattice diffractions, which correspond with the c-axis of the IGZO superlattice. Rocking curve analysis was performed on samples annealed between 700 and $1000^{\circ} \mathrm{C}$, selecting the most intense diffraction peak $\left(\begin{array}{lll}0 & 0 & 9\end{array}\right)$ at a $2 \theta$ angle of $30.84^{\circ}$. The peak maxima were normalized in order to compare peak width. As can be seen in Fig. 3 (right), the peak width decreases with increasing temperature. This confirms a larger degree of preferential c-axis orientation after annealing at higher $T$.

\section{Fig. 3}

Left: XRD diffractogram of an IGZO film sample $(m=1)$ annealed at $1000{ }^{\circ} \mathrm{C}$ for 500 s (IGZO reference: PDF nr. 00-038-1104). Right: Rocking curve analysis of the most intense diffraction peak as a function of increasing annealing temperature 

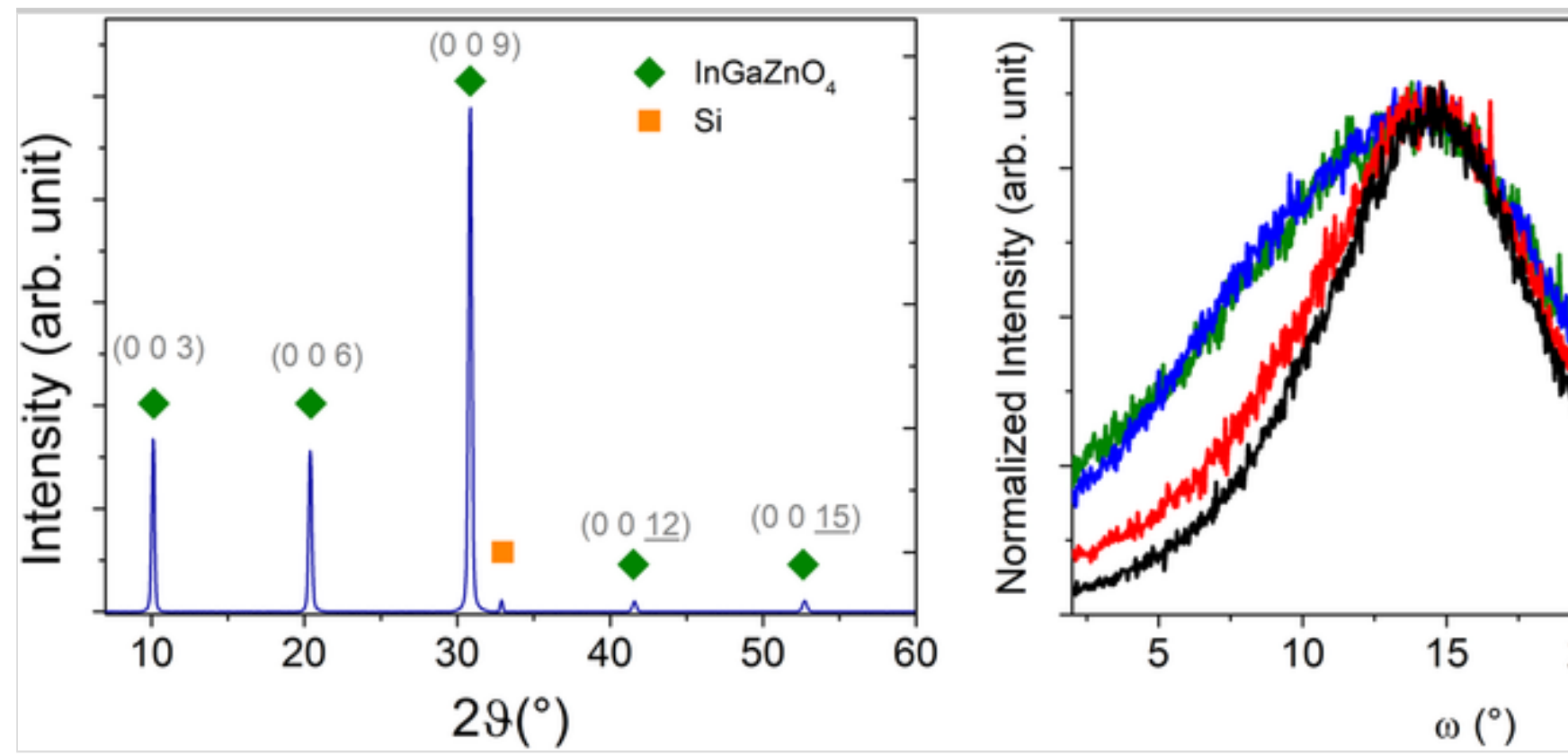

\subsection{Film morphology}

The film morphology and thickness after annealing at $1000{ }^{\circ} \mathrm{C}$ were visualized via SEM in both plane view (Fig. 4a, b) and cross-sectional mode (Fig. 4c, d). Even though the film has a visually smooth and shiny surface, it shows a rough microstructure with well-defined crystal grains. The grains have a plate-like morphology and are mostly hexagonal or trigonal in shape, which corresponds to the nature of the lattice type. Their lateral sizes vary, with diameters ranging between $100 \mathrm{~nm}$ and several micrometers. The bigger grains are typically oriented parallel to the surface, which corresponds with the observations made by XRD-analysis where a strong c-axis orientation could be observed. Even though there is a strong overlap of the plate-like grains, the film cross-section shows a relatively uniform and homogeneous layer with an average thickness of $96 \mathrm{~nm}$. For the cross-sectional case, the backscatter electron micrograph (Fig. 4d) is included to improve the visualization of the layer homogeneity and thickness.

\section{Fig. 4}

a, b Plane view secondary electron SEM micrographs of an IGZO thin film deposited using five spincoated layers and annealed at $1000^{\circ} \mathrm{C}$ for $500 \mathrm{~s}$, at two magnifications. c, d Secondary electron and backscattered electron SEM image of the film's cross section 

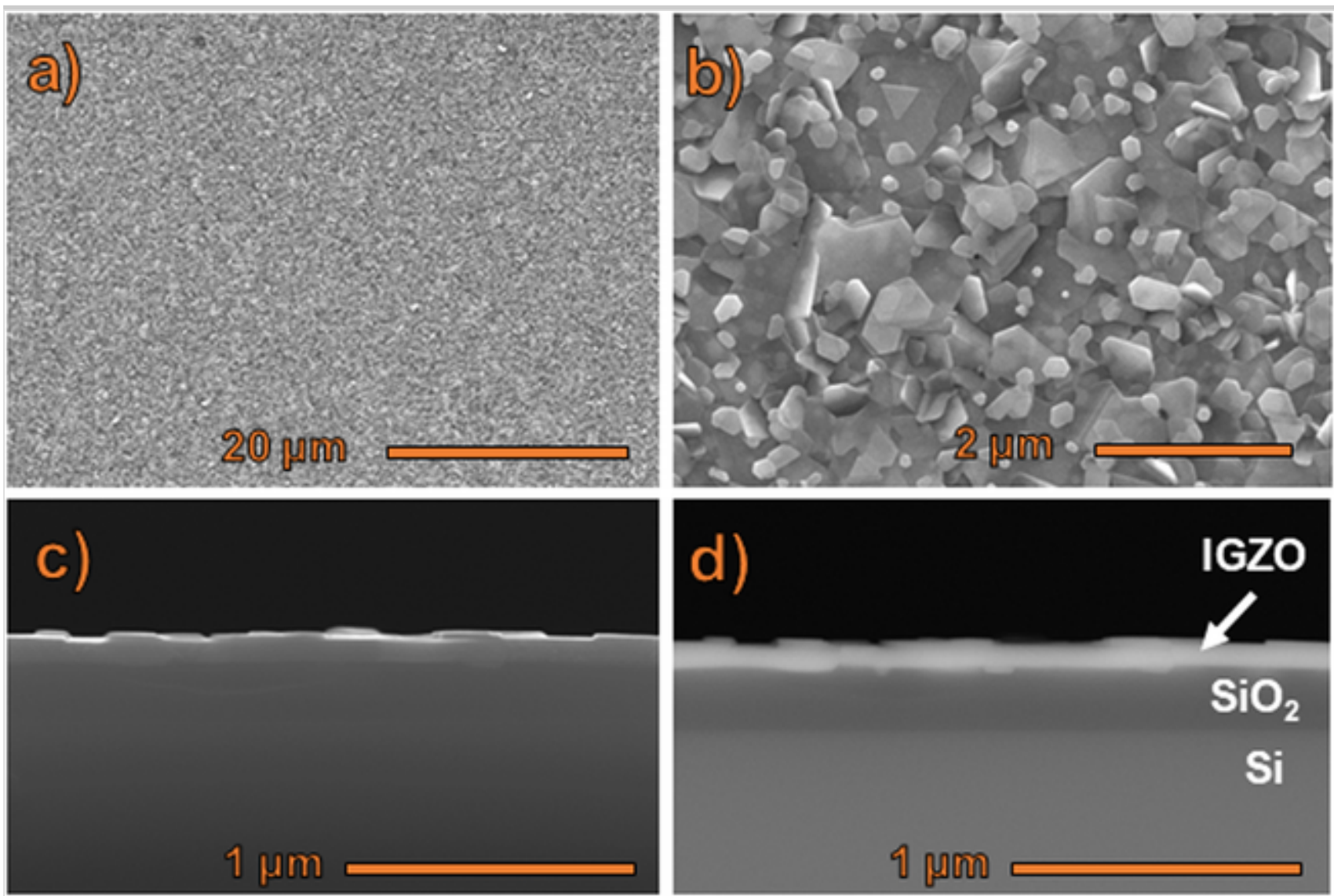

\subsection{Electrical properties}

The Hall voltage $\left(V_{\mathrm{H}}\right)$ was measured under a sweeping magnetic field. The resulting data points are shown in Fig. 5 and were fitted with a straight line $\left(R^{2}\right.$ $=0.9652)$, yielding a slope $\left(V_{\mathrm{H}} / B\right)$ of $6.26 \times 10^{-3} \mathrm{~V} / \mathrm{T}$. From this value, we could calculate a charge carrier concentration of $9.98 \times 10^{19} \mathrm{~cm}^{-3}$ and a Hall mobility of $27.2 \mathrm{~cm}^{2} / \mathrm{Vs}$. In addition, the resistivity of the sample was measured to be $2.3 \times 10^{-3} \Omega \mathrm{cm}$.

\section{Fig. 5}

$V_{\mathrm{H}}$ vs. B-plot of the IGZO film sample annealed at $1000^{\circ} \mathrm{C}$, measured using a Van der Pauw contact configuration $(I=10 \mathrm{~mA})$. The data was fitted with a straight line and the slope was extracted 


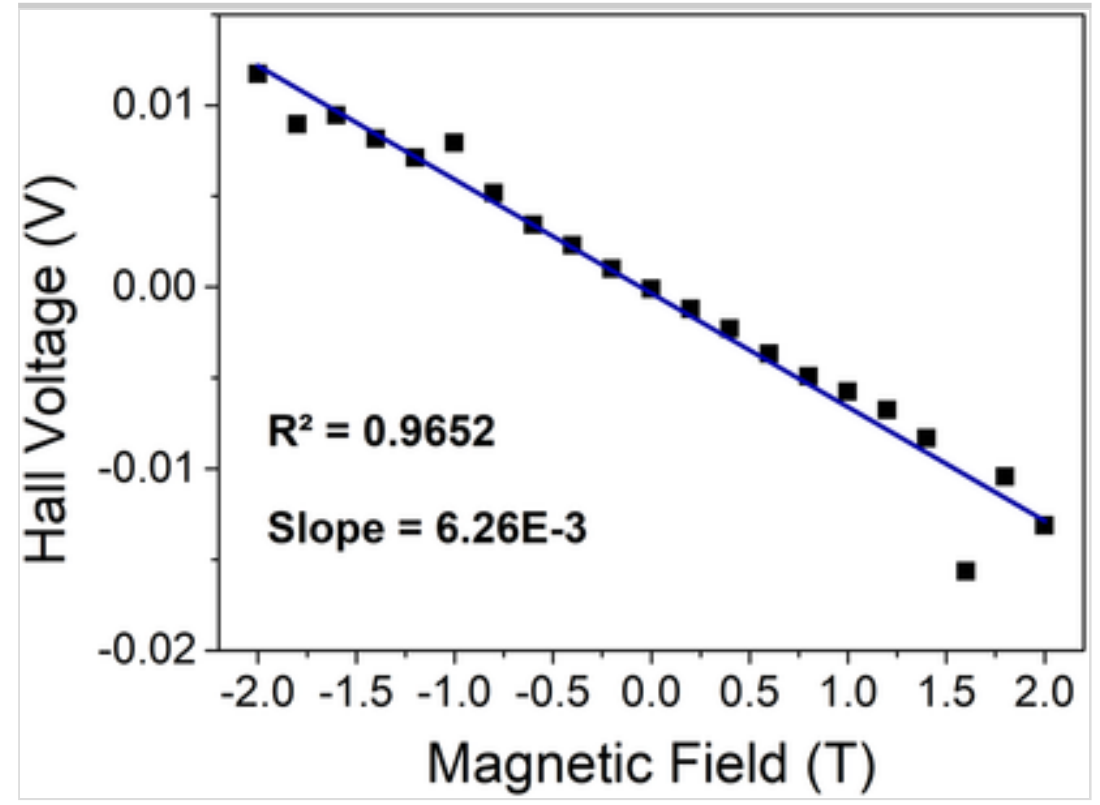

Hosono et al. identified the role of the conduction band minimum (CBM), which is localized on the metal s-orbitals, towards the conduction mechanism of IGZO $[32,33]$. Since the s-orbitals of these heavy metal ions are relatively big and show no spacial directionality due to their spherical nature, a large orbital overlap (even in the amorphous state) can be expected, leading to a higher band dispersion and improved carrier mobility. This theory is of course supported by the successful application of a-IGZO inside TFTs. For polycrystalline IGZO films, however, there will be a negative effect of the many grain boundaries on the conduction pathway efficiency, since it disrupts the metal s-orbital overlap and increases the amount of scattering sites. Despite this fact, we can still observe a relatively high carrier mobility compared to typical IGZO layers, of which selected literature values are summarized below (Table 2). It can therefore be assumed that the densification and periodic stacking of the metal ions within the crystal lattice of the grains improves the s-orbital overlap, leading to an overall lower electron effective mass and higher mobility. Another possible hypothesis for this high mobility, despite the presence of grain boundaries, is the following: Due to the strong preferential c-axis orientation, adjacent grains show an improved alignment which may facilitate inter-grain transport of charge carriers throughout the film. In a way, this describes the IGZO-phase discussed in this work as an intermediate state between polycrystalline IGZO (random orientation, low mobility) and epitaxial/single crystalline IGZO (perfect c-axis orientation, very high mobility). Along this line, the c-axis aligned IGZO layers which show promising mobility values in literature, can be placed in the latter category. It must be noted however, that mobility values retrieved from other studies are typically measured from FET devices, and are therefore often reported as field-effect mobilities. 
Overview and comparison of selected literature sources with their reported carrier mobility values

AQ1

\begin{tabular}{|c|c|c|c|c|}
\hline $\begin{array}{c}\text { Degree of } \\
\text { crystallization }\end{array}$ & Deposition method & $\begin{array}{c}\text { Temperature } \\
\left({ }^{\circ} \mathrm{C}\right)\end{array}$ & $\begin{array}{c}\text { Carrier } \\
\text { mobility* } \\
\left(\mathrm{cm}^{2} / \mathrm{Vs}\right)\end{array}$ & Reference \\
\hline \multicolumn{5}{|l|}{ (a) } \\
\hline Polycrystalline & $\begin{array}{l}\text { Nanoparticle solution } \\
\left(\mathrm{H}_{2} \mathrm{O}\right)\end{array}$ & 95 & 2.3 & {$[34]$} \\
\hline Amorphous & Solution-based (2-ME) & 450 & 6.23 & {$[35]$} \\
\hline Amorphous & Solution-based (2-ME) & 600 & 6.415 & {$[12]$} \\
\hline
\end{tabular}

Part (a) of the table corresponds to solution-processed samples

\begin{tabular}{|c|c|c|c|c|}
\hline $\begin{array}{c}\text { Degree of } \\
\text { crystallization }\end{array}$ & Deposition method & $\begin{array}{c}\text { Temperature } \\
\left({ }^{\circ} \mathrm{C}\right)\end{array}$ & $\begin{array}{l}\text { Carrier } \\
\text { mobility* } \\
\left(\mathrm{cm}^{2} / \mathrm{Vs}\right)\end{array}$ & Reference \\
\hline Amorphous & $\begin{array}{l}\text { Solution-based (2-ME) } \\
+ \text { pulsed UV-light }\end{array}$ & 350 & 7 & {$[36]$} \\
\hline Amorphous & Solution-based $\left(\mathrm{H}_{2} \mathrm{O}\right)$ & 250 & 7.73 & {$[37]$} \\
\hline Amorphous & Solution-based $\left(\mathrm{H}_{2} \mathrm{O}\right)$ & 300 & 7.9 & {$[38]$} \\
\hline Amorphous & Solution-based (2-ME) & $350-500$ & $20-30$ & {$[15]$} \\
\hline Polycrystalline & Solution-based $\left(\mathrm{H}_{2} \mathrm{O}\right)$ & 1000 & 27.2 & This work \\
\hline Amorphous & Solution-based (2-ME) & 300 & $20-50$ & {$[14]$} \\
\hline \multicolumn{5}{|l|}{ (b) } \\
\hline CAAC & DC sputtering & 300 & 7.3 & {$[39]$} \\
\hline Polycrystalline & $\begin{array}{l}\text { RF-magnetron } \\
\text { sputtering }\end{array}$ & 950 & 14.7 & {$[3]$} \\
\hline Amorphous & $\begin{array}{l}\text { RF-magnetron } \\
\text { sputtering }\end{array}$ & 450 & 15.8 & {$[40]$} \\
\hline Amorphous & $\begin{array}{l}\text { RF-magnetron } \\
\text { sputtering + UV-thermal } \\
\text { treatment }\end{array}$ & 150 & 16.2 & {$[41]$} \\
\hline Amorphous & $\begin{array}{l}\text { RF-magnetron } \\
\text { sputtering }\end{array}$ & 300 & 17.4 & {$[42]$} \\
\hline $\begin{array}{l}\text { Amorphous }+ \\
\text { CAAC dual layer }\end{array}$ & $\begin{array}{l}\text { RF-magnetron } \\
\text { sputtering }\end{array}$ & 310 & 20.6 & {$[43]$} \\
\hline Amorphous & $\begin{array}{l}\text { RF-magnetron } \\
\text { sputtering + laser spike }\end{array}$ & 430 & 73.5 & {$[44]$} \\
\hline
\end{tabular}


Part (a) of the table corresponds to solution-processed samples

\subsection{Optical properties}

The optical transparency of the IGZO film was investigated by depositing a layer of equal thickness on a fused silica substrate followed by annealing at $1000{ }^{\circ} \mathrm{C}$ (Fig. 6). The blank substrate showed a transparency of $93 \%$ in the visible light range (with air used as a background). The IGZO film on fused silica showed a similar transparency in the amorphous state $\left(600^{\circ} \mathrm{C}\right)$. After annealing at 1000 ${ }^{\circ} \mathrm{C}$, the visible-light transparency decreases slightly towards values between $71.6 \%(400 \mathrm{~nm})$ and $85.0 \%(800 \mathrm{~nm})$. This loss in transparency can be explained by the increase of sample roughness due to grain formation, as seen in the SEM results. This results in a larger degree of scattering at the grain boundaries, which decreases the specular transmittance.

\section{Fig. 6}

UV-Vis-NIR transmission spectra of the IGZO film vs. air, before and after annealing. The blank spectrum for the fused silica substrate is provided as a reference

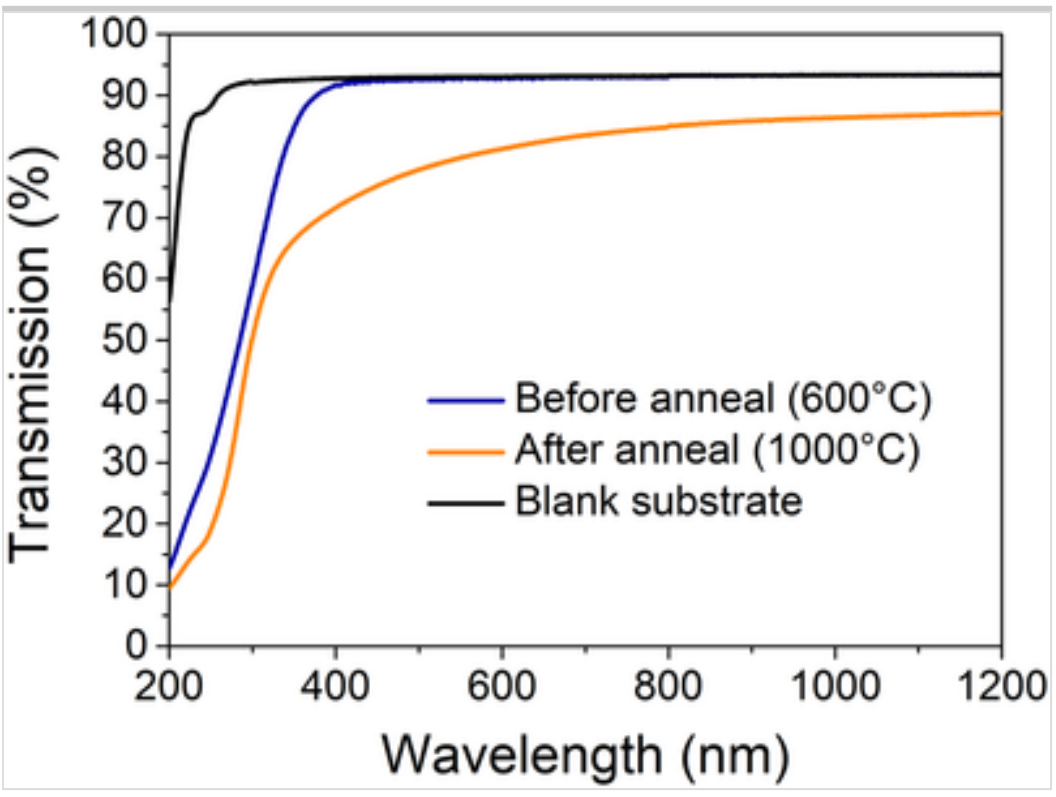

\section{Conclusions}

A polycrystalline rhombohedral IGZO film with a preferential c-axis orientation was obtained by solution-deposition, starting from a stable aqueous multimetal 
citrate precursor system. We hereby provide a safe and sustainable alternative to 2-ME based precursors, which additionally often contain nitrates. After careful tuning of the processing steps, the study shows that at the cost of a higher thermal budget and a slightly increased surface roughness, a significant gain in carrier mobility compared to typical solution-processed amorphous IGZO films can be achieved. This result suggests that, despite the abundant presence of grain boundaries inside the film, a dense and periodic stacking of the metal ions inside the lattice is highly beneficial towards an overall increase of the electron mobility throughout the conduction pathway. The logical next step is the implementation of these polycrystalline IGZO layers in devices in order to further quantify and compare their performance versus the more commonly studied a-IGZO layers.

\section{Acknowledgements}

This research is financially supported by the Research Foundation-Flanders (FWO Vlaanderen, project nr. G054312N). The authors would like to thank Bart Ruttens for performing the rocking curve measurements.

Compliance with ethical standards

Conflict of interest The authors declare that they have no conflict of interest.

\section{References}

1. Petti L, Münzenrieder N, Vogt C, Faber H, Büthe L, Cantarella G, Bottacchi F, Anthopoulos TD, Tröster G (2016) Metal oxide semiconductor thin-film transistors for flexible electronics. Appl Phys Rev 3(2):021303. https://doi.org/10.1063/1.4953034

2. Kato K, Shionoiri Y, Sekine Y, Furutani K, Hatano T, Aoki T, Sasaki M, Tomatsu H, Koyama J, Yamazaki S (2012) Evaluation of off-state current characteristics of transistor using oxide semiconductor material, indiumgallium-zinc oxide. Jpn J Appl Phys 51:021201.

https://doi.org/10.1143/jjap.51.021201

3. Li Q, Song ZX, Ma F, Li YH, Xu KW (2015) Effects of high-temperature thermal annealing on the electronic properties of In-Ga-Zn oxide thin films. J Vac Sci Technol A: Vac, Surf, Films 33(2):021520.

https://doi.org/10.1116/1.4908157

4. Li CF, Bando Y, Nakamura M, Onoda M, Kimizuka N (1998) Modulated structures of homologous compounds $\operatorname{InMO} 3(\mathrm{ZnO})(\mathrm{m})(\mathrm{M}=\mathrm{In}, \mathrm{Ga}$; 
$\mathrm{m}=$ integer) described by four-dimensional superspace group. J Solid State Chem 139(2):347-355. https://doi.org/10.1006/jssc.1998.7856

5. Nomura K, Ohta H, Ueda K, Kamiya T, Orita M, Hirano M, Suzuki T, Honjyo C, Ikuhara Y, Hosono H (2004) Growth mechanism for singlecrystalline thin film of $\mathrm{InGaO} 3(\mathrm{ZnO})(5)$ by reactive solid-phase epitaxy. J Appl Phys 95(10):5532-5539. https://doi.org/10.1063/1.1712010

6. Ogo Y, Nomura K, Yanagi H, Ohta H, Kamiya T, Hirano M, Hosono H (2006) Growth and structure of heteroepitaxial thin films of homologous compounds RAO3(MO)m by reactive solid-phase epitaxy: applicability to a variety of materials and epitaxial template layers. Thin Solid Films 496(1):64-69. https://doi.org/10.1016/j.tsf.2005.08.201

7. Ohta H, Nomura K, Orita M, Hirano M, Ueda K, Suzuki T, Ikuhara Y, Hosono H (2003) Single-crystalline films of the homologous series $\mathrm{InGaO} 3(\mathrm{ZnO})(\mathrm{m})$ grown by reactive solid-phase epitaxy. Adv Funct Mater 13(2):139-144. https://doi.org/10.1002/adfm.200390020

8. Chen HG, Lin YS (2013) Epitaxial growth of superlattice YbGaO3(ZnO) (5) and $\mathrm{InGaO} 3(\mathrm{ZnO})(5)$ films by the combination of sputtering and reactive solid phase epitaxy. Thin Solid Films 545:33-37.

https://doi.org/10.1016/j.tsf.2013.06.081

9. Nomura K, Ohta H, Ueda K, Kamiya T, Hirano M, Hosono H (2003) Thinfilm transistor fabricated in single-crystalline transparent oxide semiconductor. Science 300(5623):1269-1272.

https://doi.org/10.1126/science.1083212

10. Yamazaki S (2012) New crystalline structure yields reliable thin-film transistors. SPIE Newsroom:1-3. https://doi.org/10.1117/2.1201209.004452

11. Yamazaki S, Hirohashi T, Takahashi M, Adachi S, Tsubuku M, Koezuka J, Okazaki K, Kanzaki Y, Matsukizono H, Kaneko S, Mori S, Matsuo T (2014) Back-channel-etched thin-film transistor using c-axis-aligned crystal In-Ga-Zn oxide. J Soc Inf Disp 22(1):55-67. https://doi.org/10.1002/jsid.211

12. Hwang S, Lee JH, Woo CH, Lee JY, Cho HK (2011) Effect of annealing temperature on the electrical performances of solution-processed InGaZnO thin film transistors. Thin Solid Films 519(15):5146-5149. https://doi.org/10.1016/j.tsf.2011.01.074 
13. Cho SW, Kim JH, Shin S, Cho HH, Cho HK (2013) All-solutionprocessed $\mathrm{InGaO} 3(\mathrm{ZnO}) \mathrm{m}$ thin films with layered structure. J Nanomater 2013:1-6. https://doi.org/10.1155/2013/909786

14. Everaerts K, Zeng L, Hennek JW, Camacho DI, Jariwala D, Bedzyk MJ, Hersam MC, Marks TJ (2013) Printed indium gallium zinc oxide transistors. Self-assembled nanodielectric effects on low-temperature combustion growth and carrier mobility. ACS Appl Mater Interfaces 5(22):11884-11893. https://doi.org/10.1021/am403585n

15. Street RA, Ng TN, Lujan RA, Son I, Smith M, Kim S, Lee T, Moon Y, Cho S (2014) Sol-gel solution-deposited InGaZnO thin film transistors. ACS Appl Mater Interfaces 6(6):4428-4437. https://doi.org/10.1021/am500126b

16. Yoon S, Kim SJ, Tak YJ, Kim HJ (2017) A solution-processed quaternary oxide system obtained at low-temperature using a vertical diffusion technique. Sci Rep 7:43216. https://doi.org/10.1038/srep43216

17. 2-methoxyethanol safety data sheet. (2017) Fisher scientific. https://www.fishersci.com/store/msds? partNumber $=$ AC396891000\&productDescription $=2-$ METHOXYETHANOL\&vendorId=VN00032119\&countryCode $=$ US\&language $=\mathrm{en}$

18. Wohlfarth C (2008) Dielectric constant of 2-methoxyethanol. In: Lechner MD (ed) Data extract from Landolt-Börnstein IV/17: Static dielectric constants of pure liquids and binary liquid mixtures. Springer Materials, AQ2

19. Mondelaers D (2003) PhD Thesis: The synthesis and characterization of $\mathrm{ZnO}$ nanopowders and thin films prepared from an aqueous solution.

UHasselt, Diepenbeek, Belgium

20. Sillén LG, Martell AE (1971) Stability constants of metal-ion complexes. Chemical Society,

AQ3

21. Van Bael MK, Hardy A, Mullens J (2013) Aqueous precursor systems. In: Schneller T, Waser R, Kosec M, Payne D (eds) Chemical solution deposition of functional oxide thin films. Springer,

22. Clausen M, Ohman LO, Persson P (2005) Spectroscopic studies of aqueous gallium(III) and aluminum(III) citrate complexes. J Inorg Biochem 
99(3):716-726. https://doi.org/10.1016/j.jinorgbio.2004.12.007

23. Feng TL, Gurian PL, Healy MD, Barron AR (1990) Aluminum citrate isolation and structural characterization of a stable trinuclear complex. Inorg Chem 29(3):408-411. https://doi.org/10.1021/ic00328a013

24. Matzapetakis M, Kourgiantakis M, Dakanali M, Raptopoulou CP, Terzis A, Lakatos A, Kiss T, Banyai I, Iordanidis L, Mavromoustakos T, Salifoglou A (2001) Synthesis, $\mathrm{pH}$-dependent structural characterization, and solution behavior of aqueous aluminum and gallium citrate complexes. Inorg Chem 40(8):1734-1744. https://doi.org/10.1021/ic0004611

25. Kim Y, Koo HG, Shin DH, Park LO, Lee JH, Jang HG, Kim C (2010) Zinc citrate with alkali metal and ammonium cations: Crystal structure of K-4 Zn(Citrate)(2). J Struct Chem 51(2):382-385. https://doi.org/10.1007/s10947010-0056-5

26. Swanson R, Ilsley WH, Stanislowski AG (1983) Crystal-structure of zinc citrate. J Inorg Biochem 18(3):187-194. https://doi.org/10.1016/01620134(83)85001-6

27. Capone S, Derobertis A, Destefano C, Sammartano S (1986) Formation and stability of zinc(ii) and cadmium(ii) citrate complexes in aqueoussolution at various temperatures. Talanta 33(9):763-767. https://doi.org/10.1016/0039-9140(86)80184-9

28. Fujii T, Albarede F (2012) Ab Initio Calculation of the Zn Isotope Effect in Phosphates, Citrates, and Malates and Applications to Plants and Soil. PLoS ONE 7(2):5. https://doi.org/10.1371/journal.pone.0030726

29. Ivanova VY, Chevela VV, Bezryadin SG (2015) Complex formation of indium(III) with citric acid in aqueous solution. Russ Chem Bull 64(8):18421849

30. Van Werde K, Mondelaers D, Vanhoyland G, Nelis D, Van Bael MK, Mullens J, Van Poucke LC, Van der Veken B, Desseyn HO (2002) Thermal decomposition of the ammonium zinc acetate citrate precursor for aqueous chemical solution deposition of ZnO. J Mater Sci 37(1):81-88. https://doi.org/10.1023/a:1013141723764

31. Peys N (2014) PhD Thesis: How to master vanadium oxide stoichiometry and phase formation? Insights in the aqueous precursor chemistry. UHasselt, 
Diepenbeek, Belgium

32. Hosono H, Kikuchi N, Ueda N, Kawazoe H (1996) Working hypothesis to explore novel wide band gap electrically conducting amorphous oxides and examples. J Non-Cryst Solids 200:165-169

33. Hosono H (2006) Ionic amorphous oxide semiconductors: material design, carrier transport, and device application. J Non-Cryst Solids 352(920):851-858. https://doi.org/10.1016/j.jnoncrysol.2006.01.073

34. Ya-Hui Y, Yang SS, Chen-Yen K, Kan-San C (2010) Chemical and electrical properties of low-temperature solution-processed In- Ga-Zn-O thin-film transistors. IEEE Electron Device Lett 31(4):329-331. https://doi.org/10.1109/led.2010.2041425

35. Kim GH, Jeong WH, Kim HJ (2010) Electrical characteristics of solution-processed $\mathrm{InGaZnO}$ thin film transistors depending on $\mathrm{Ga}$ concentration. Phys Status Solidi A 207(7):1677-1679.

https://doi.org/10.1002/pssa.200983742

36. Benwadih M, Coppard R, Bonrad K, Klyszcz A, Vuillaume D (2016) High mobility flexible amorphous IGZO thin-film transistors with a low thermal budget ultra-violet pulsed light process. ACS Appl Mater Interfaces $8(50): 34513-34519$

37. Choi C, Baek Y, Lee BM, Kim KH, Rim YS (2017) Enhanced electrical stability of nitrate ligand-based hexaaqua complexes solution-processed ultrathin a-IGZO transistors. J Phys D-Appl Phys 50(48):8. https://doi.org/10.1088/1361-6463/aa9357

38. Xie M, Wu S, Chen Z, Khan Q, Wu X, Shao S, Cui Z (2016) Performance improvement for printed indium gallium zinc oxide thin-film transistors with a preheating process. RSC Adv 6(47):41439-41446. https://doi.org/10.1039/c6ra01776b

39. Matsuda S, Kikuchi E, Yamane Y, Okazaki Y, Yamazaki S (2015) Channel length dependence of field-effect mobility of c-axis-aligned crystalline In-Ga-Zn-O field-effect transistors. Jpn J Appl Phys 54(4):4. https://doi.org/10.7567/jjap.54.041103

40. Liu C, Wei M, Jia Z, Deng Y-F, Liu H, Deng H (2014) Improvements in the performances of In- $\mathrm{Ga}-\mathrm{Zn}-\mathrm{O}$ thin-film transistors on glass substrates by 
annealing treatment. J Mater Sci: Mater Electron 25(12):5535-5539. https://doi.org/10.1007/s10854-014-2340-1

41. Tak YJ, Park SP, Jung TS, Lee H, Kim W-G, Park JW, Kim HJ (2016) Reduction of activation temperature at $150^{\circ} \mathrm{C}$ for IGZO films with improved electrical performance via UV-thermal treatment. J Inf Disp 17(2):73-78. https://doi.org/10.1080/15980316.2016.1172524

42. Jeon J-H, Gong T-K, Kong Y-M, Lee HM, Kim D (2015) Effect of postdeposition annealing on the structural, optical and electrical properties of IGZO films. Electron Mater Lett 11(3):481-484.

https://doi.org/10.1007/s13391-014-4410-1

43. Chung CY, Zhu B, Greene RG, Thompson MO, Ast DG (2015) High mobility, dual layer, c-axis aligned crystalline/amorphous IGZO thin film transistor. Appl Phys Lett 107(18):5. https://doi.org/10.1063/1.4935026

44. Chung C-Y, Zhu B, Ast DG, Greene RG, Thompson MO (2015) High mobility amorphous InGaZnO4 thin film transistors formed by $\mathrm{CO}_{2}$ laser spike annealing. Appl Phys Lett 106(12):123506.

https://doi.org/10.1063/1.4914373 